\title{
Salvage of Infected Cardiac Implantable Electrical Devices with Subpectoral Plane Pocket Revision
}

\author{
Samiksha Mehare ${ }^{1}$ \\ ${ }^{1}$ Department of Plastic and Reconstructive Surgery, Army Hospital \\ (R \& R) Delhi Cantt, India \\ 2Department of Surgery, Army Hospital (R \& R) Delhi Cantt, India \\ ${ }^{3}$ Department of Surgery, Command Hospital (NC), Udhampur, \\ Jammu and Kashmir, India
}

Pallab Chatterjee ${ }^{1}$ Anuj Kumar Sharma ${ }^{2}$ Pranay Pratap ${ }^{1} \quad$ Ajay Dabas $^{3} \quad$ Bharat Mishra ${ }^{1}$

Indian J Plast Surg 2021;54:344-349.

\begin{abstract}
Address for correspondence Pranay Pratap, MCh, Department of Plastic and Reconstructive Surgery, Army Hospital (R\&R), Delhi-Cantt- 110010, India (e-mail: pranaypratap2@gmail.com).
\end{abstract}

\begin{abstract}
Introduction Infection of cardiac implantable electrical devices (CIEDs) may lead to serious complications. Complete CIED explantation is expensive, requires expertise, not free from complications, and may not be an option in patients with device dependence.

Aim To highlight that carefully selected infected CIEDs can be salvaged by placing the device in a subpectoral pocket below the pectoralis major muscle. We conducted a retrospective descriptive observational study.

Material and Methods Twelve patients (10 male and two female) with erosion, exposure or infection of infraclavicular, subcutaneously placed CIED were treated over a 30-month period between July 2018 and December 2020. The technique involved debridement and excision of a peridevice capsule, creating a subpectoral pocket beneath the pectoralis major muscle, and placing the CIED in a new pocket with total muscle coverage and closure of skin without tension.

Results Twelve patients ( $m=10 ; f=2$ ) with a mean age of 65 years (range, 46-82 years) presented with infection of CIED within 9 months of implantation. None

Keywords

- CIED infection

- CIED salvage

- subpectoral CIED implantation

- pectoralis major muscle had sepsis or endocarditis. In nine patients, CIEDs were successfully salvaged with relocation to subpectoral pocket. Mean follow-up was 20 months (range, 8-30 months). Three out of 12 developed reinfection that ultimately required CIED explantation. There was no mortality.

Conclusion In the absence of sepsis or endocarditis, infected CIEDs may be attempted at salvage by subpectoral pocket placement. This obviates the need for potentially risky explantation or replacement of expensive CIEDs.
\end{abstract}

\section{Introduction}

With increasing life expectancy and progress in the understanding of the electrophysiology of the heart, there is an increase in the number of the cardiac implantable electrical

DOI https://doi.org/ $10.1055 / \mathrm{s}-0041-1735417$ ISSN 0970-0358 devices (CIEDs) implanted. ${ }^{1-3}$ The placement is usually done in the infraclavicular subcutaneous plane, according to the recommended guidelines. ${ }^{4,5}$

Unfortunately, there has been an increase in the infection rates also. ${ }^{6}$ Managing CIED infections remain complex and

(C) 2021. Association of Plastic Surgeons of India.

This is an open access article published by Thieme under the terms of the Creative Commons Attribution-NonDerivative-NonCommercial-License, permitting copying and reproduction so long as the original work is given appropriate credit. Contents may not be used for commercial purposes, or adapted, remixed, transformed or built upon. (https://creativecommons.org/licenses/by-nc-nd/4.0/).

Thieme Medical and Scientific Publishers Pvt. Ltd. A-12, 2nd Floor, Sector 2, Noida-201301 UP, India 
debatable despite published guidelines. Current guidelines recommend explantation and reimplanting a fresh generator device after the control of infection. ${ }^{7}$ However, removal of the CIEDs, especially the leads, is also fraught with danger with potentially fatal complications and additional cost ${ }^{8}$. Many investigators have attempted salvage by treating the pocket infection surrounding the CIED, changing the generator device and relocation into a new subcutaneous pocket without removal of atrioventricular (AV) leads. ${ }^{9-12}$ As explanting CIEDs is an expensive proposition, there is a felt need of salvaging infected CIEDs.

The use of muscle flaps is a time-tested technique in the treatment of deep-seated bone, joint, or prosthetic infections in plastic surgery. ${ }^{13}$ We surmised that the placement of infected CIED beneath the pectoralis major (PM) muscle would be an effective salvage strategy by providing vascularized cover to the infected device and eradicating the local infection without the need to explant the device.

We present our study with an aim to highlight that carefully selected infected CIEDs can be salvaged by placing the device in a subpectoral pocket below the pectoralis major muscle.

\section{Material and Methods}

A retrospective descriptive observational study was performed with 12 patients treated over 30 months from June 2018 through December 2020, with follow-up ranging from 8 to 30 months (mean follow-up: 20 months). The standard definitions were used for the inclusion and exclusion criteria. $5,7,14$

Inclusion criteria: isolated generator pocket infection and isolated pocket erosion, that is, those without evidence of systemic infection (normal total leucocyte count [TLC], no fever, negative blood cultures, no evidence of vegetations on 2D echocardiography [2D ECHO] and transesophageal echocardiography [TEE]).

Patients with raised TLC, fever, positive blood culture or vegetations on 2D ECHO and/or TEE were excluded from the study. These were the patients with bacteremia, pocket site infection with bacteremia, lead infection, pocket site infection with lead/valvular endocarditis, positive blood cultures, lead or valvular vegetation, and CIED endocarditis. Patients with prosthetic heart valves and end-stage renal disease patients on dialysis were also excluded. Patients who refused intervention after explanation of the procedure as part of informed consent were also excluded.

\section{Surgical Technique}

The procedures were performed under general anesthesia or conscious sedation with local anesthesia. Antiplatelet drugs like clopidogrel or aspirin were not discontinued. The infraclavicular involved pocket area was infiltrated with $0.5 \%$ lignocaine in normal saline containing 1:200,000 epinephrine. The CIED along with the clump of leads was brought out of the pocket. Using sharp dissection with utmost caution, total excision of the peridevice and lead system capsule was done. The whole pocket was irrigated with gentamicin-saline solution. The device and the leads were also irrigated, and biofilm removed (-Fig. 1).

The fibers of the PM were split (not cut!) with blunt dissection ( - Fig. 2). A subpectoral pocket was created to
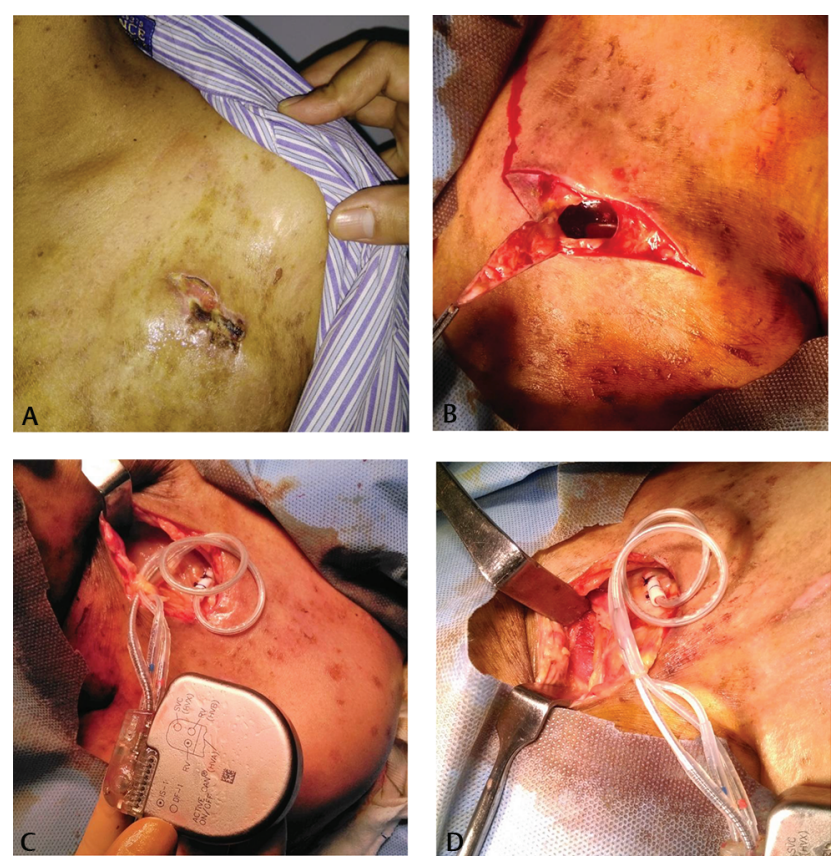

Fig. 1 Salvage of infected cardiac implantable electronic device (CIED): debridement. (A) Skin necrosis and purulent discharge from the subcutaneous pocket. (B) Excision and deroofing of subcutaneous pocket. (C) Exteriorization of the generator unit and the lead system. (D) Thorough debridement and irrigation of the subcutaneous pocket done.
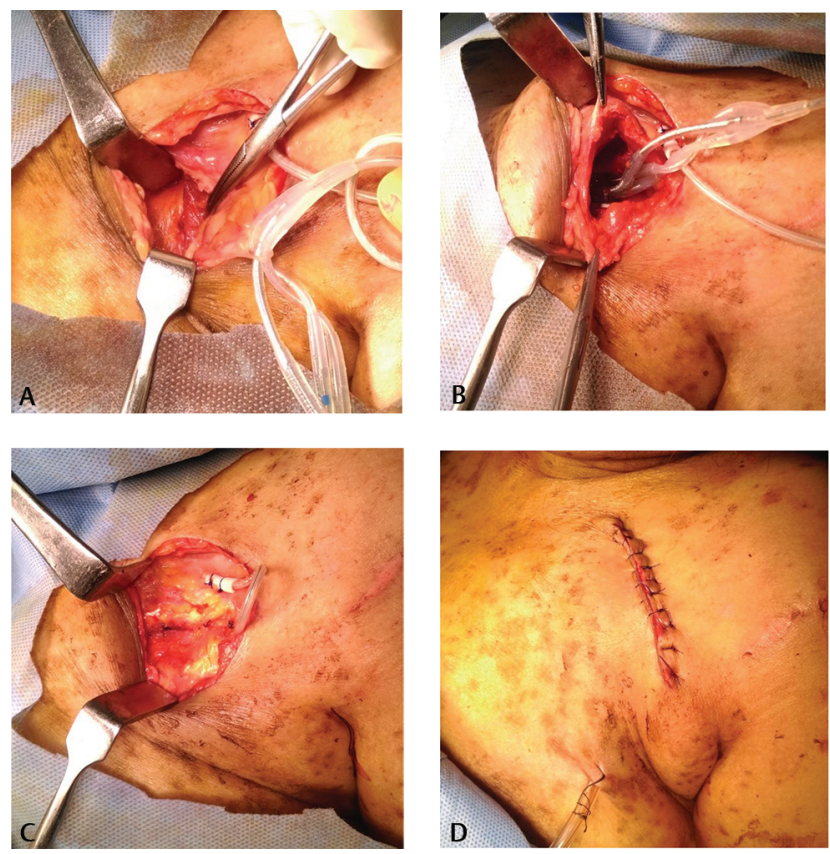

Fig. 2 Salvage of infected cardiac implantable electronic device (CIED): placement in subpectoral pocket. (A) The pectoralis major (PM) muscle fibers are split by blunt dissection to reach subpectoral plane. (B) CIED being placed in the subpectoral pocket. (C) Coverage of CIED by muscle obtained by suturing back the split fibers. (D) Skin closure over the suction drain in situ. 
accommodate CIED and all the leads. After subpectoral placement, the split fibers were sutured together with interrupted absorbable sutures to provide total coverage by the PM muscle. The skin wound was closed in two layers over a $14 \mathrm{G}$ suction drain. The skin was closed without any tension and simple undermining and advancement of surrounding skin, obviating the need to design any complicated local flaps (-Figs. 2, 3). Dressings were applied and the arm was splinted in adduction.

Parenteral antibiotics were continued for 14 days after the procedure. The skin sutures were removed after 2 weeks. A follow-up schedule was advised to the patients, usually every 2 months for 1year, and later, once in 6 months.
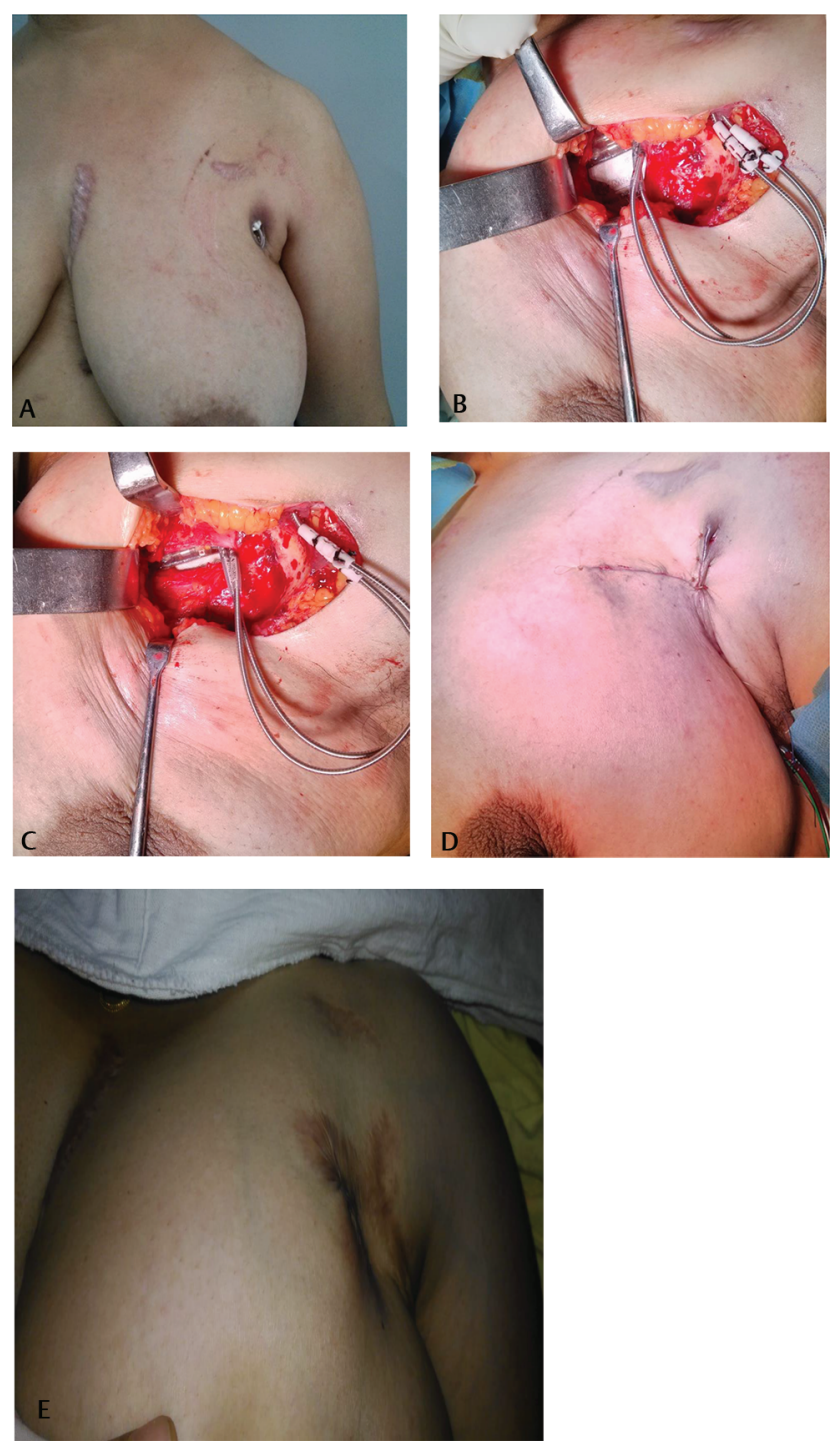

Fig. 3 Salvage of exposed cardiac implantable electronic device (CIED) with no purulence. (A) Device dependant patient with exposure of the implant with no option of explantation. (B) After debridement, subpectoral pocket is created and the device placed. (C) CIED placed in the pocket and covered by the vascularized pectoralis major (PM) muscle. (D) Final tension-free skin wound closure over suction drain. (E) Stable CIED coverage with no recurrence at 30 months follow-up.

\section{Results}

A total of 12 patients were treated. Ten patients were male and two were female. The age ranged from 46 to 82 years (mean age 65 years). The time from CIED placement to the exposure or infection ranged from 3 weeks to 9 months (mean 4 months). Follow-up of ranged from 6 to 34 months (mean follow-up: 20 months) (-Table 1).

In nine of the 12 (75\%) patients, we achieved successful salvage of the devices with uneventful healing. Three patients developed discharging sinus within 12 weeks of the surgical procedure, signifying treatment failure. Two had presented with purulent discharge at the first instance, and one with warmth and erythema. One of these three was maintained on antibiotic therapy during the exacerbations, and CIED was subsequently explanted 9 months later. The other two patients were treated with complete explantation and reimplantation of a new device on the contralateral side, owing to persistent discharging sinus.

During the same period, six patients underwent explantation of infected CIEDs as the primary treatment procedure. Five of them were unwilling to undergo the salvage procedure and opted for explantation, as per the guidelines in cardiology. One had endocarditis (vegetations on TEE), required sternotomy, and was therefore not a candidate for the salvage procedure.

\section{Discussion}

Explantation of infected CIED is not completely safe. Both morbidity and mortality have been reported during explantations. The explantations may even need sternotomy and thoracotomies, with their attendant morbidities in complicated cases. ${ }^{14-16}$ Sohail et al $^{15}$ reported results of 185 cases where CIEDs were completely extracted. Twenty-five patients (13.7\%) developed serious complications with two deaths. Sternotomy was required in 19 cases. Rusanov et $\mathrm{al}^{16}$ shared their experience of 15 years of CIED extraction. Leads and patch removal was completely successful in only $86 \%$ cases. They had $11 \%$ complications and two deaths. Thoracotomy and sternotomy were used in $18 \%$ cases. In a study of 412 patients with a device and leads removal, Tarakaji et al reported 19 deaths, and two were directly related to device extraction. ${ }^{17}$ The complication rate was $38.9 \%$ in their series.

Specialized technique and instruments are required for CIED and lead system explantation. ${ }^{18}$ Despite this, it may not always be successful. ${ }^{15,16,19}$ Moreover, it should be attempted by experienced operators dealing with a large number of such cases. It, most importantly, warrants a surgical backup. ${ }^{18}$

CIED infection has been recognized as a spectrum, and not one single entity, depending upon patient's comorbid conditions, virulence, and type of microbial infection. ${ }^{7,14,20}$ Complete explantation is not the only and the first answer for all infections. A course of antibiotics is the first line of treatment and may be the only treatment required for certain subgroups. ${ }^{7,19}$ 
Table 1 Time of presentation after implantation, age, type of CIED, wound characteristics and outcomes

\begin{tabular}{|c|c|c|c|c|c|c|c|}
\hline No. & $\begin{array}{l}\text { Time of } \\
\text { presentation } \\
\text { after implantation }\end{array}$ & $\begin{array}{l}\text { Type of } \\
\text { CIED }\end{array}$ & $\begin{array}{l}\text { Age/Sex } \\
\text { (year/M or F) }\end{array}$ & $\begin{array}{l}\text { Local clinical } \\
\text { examination }\end{array}$ & $\begin{array}{l}\text { Discharge } \\
\text { from wound }\end{array}$ & $\begin{array}{l}\text { Culture from } \\
\text { wound }\end{array}$ & $\begin{array}{l}\text { Outcome on } \\
\text { follow-up }\end{array}$ \\
\hline 1 & 2 months & DDDRO & $64 / M$ & $\begin{array}{l}\text { Exposure of device } \\
\text { with minimal } \\
\text { erythema }\end{array}$ & $\begin{array}{l}\text { Minimal } \\
\text { serous }\end{array}$ & $\begin{array}{l}\text { Coagulase negative } \\
\text { staphylococcus }\end{array}$ & Healed \\
\hline 2 & 6 months & AICD & $46 / \mathrm{F}$ & Exposed device & Serous & Skin commensals & Healed \\
\hline 3 & 2 months & CRT-D & $73 / \mathrm{M}$ & Exposed device & Nil & $\begin{array}{l}\text { Mixed growth } \\
\text { (Staph aureus) }\end{array}$ & Healed \\
\hline 4 & 6 months & DDDRO & $62 / \mathrm{M}$ & $\begin{array}{l}\text { Exposed device, } \\
\text { warmth, pus } \\
\text { discharge }\end{array}$ & Purulent & No growth & Explantation \\
\hline 5 & 8 months & CRT-P & $71 / \mathrm{F}$ & $\begin{array}{l}\text { Exposed device, local } \\
\text { warmth and minimal } \\
\text { erythema }\end{array}$ & Serous & $\begin{array}{l}\text { Coagulase negative } \\
\text { staphylococcus }\end{array}$ & Healed \\
\hline 6 & 2 months & AICD & $64 / M$ & $\begin{array}{l}\text { Exposure of device } \\
\text { with minimal } \\
\text { erythema }\end{array}$ & Nil & $\begin{array}{l}\text { Coagulase negative } \\
\text { staphylococcus }\end{array}$ & Healed \\
\hline 7 & 3 months & $\begin{array}{l}\text { Single } \\
\text { chamber } \\
\text { pace- } \\
\text { maker }\end{array}$ & $71 / \mathrm{M}$ & $\begin{array}{l}\text { Exposure of device } \\
\text { with minimal } \\
\text { erythema }\end{array}$ & Serous & Skin commensals & Healed \\
\hline 8 & 1 month & $\mathrm{AICD}$ & $56 / \mathrm{M}$ & $\begin{array}{l}\text { Exposed device with } \\
\text { pus discharge }\end{array}$ & Purulent & $\begin{array}{l}\text { Mixed growth } \\
\text { (Staph aureus) }\end{array}$ & Explantation \\
\hline 9 & 09 months & CRT-D & $67 / M$ & $\begin{array}{l}\text { Pain and erythema } \\
\text { over the incision } \\
\text { with impending } \\
\text { exposure }\end{array}$ & Nil & No growth & Healed \\
\hline 10 & 3 months & AICD & $53 / \mathrm{M}$ & Exposed device & $\mathrm{Nil}$ & No growth & Healed \\
\hline 11 & 03 weeks & DDDRO & $82 / M$ & $\begin{array}{l}\text { Exposed device with } \\
\text { erythema of skin }\end{array}$ & Nil & Mixed growth & Healed \\
\hline 12 & 5 months & $\mathrm{AICD}$ & $72 / \mathrm{M}$ & $\begin{array}{l}\text { Exposed device with } \\
\text { erythema and puru- } \\
\text { lent discharge }\end{array}$ & Purulent & No growth & Explantation \\
\hline
\end{tabular}

Abbreviations: AICD, automated implantable cardioverter device; CIED, cardiac implantable electronic device; CRT-D, cardiac resynchronization therapy device; DDDRO, dual chamber pacing device.

A subgroup of infected CIEDs may be salvaged with surgical procedures. Gupta et al could salvage 80 percent implants using rectus abdominis flaps..$^{21}$ They used CT scan to identify the lead infection, and the salvage of the implant was judiciously done to a good measure. There was no mortality in their series. Taylor and colleagues ${ }^{20}$ reported the successful treatment of a pocket infection with pocket revision and placement of continuous irrigation system. Closed antibiotic irrigation system was used successfully for lead preservation by Hurst et al, ${ }^{10}$ whereas Lee and associates ${ }^{11}$ used the same technique for lead system and generator preservation. Har-Shai et $\mathrm{al}^{22}$ used subcapsular relocation of the generator and lead systems. Similarly, Yamada and colleagues $^{9}$ described successful salvage of lead systems, with success in 17 of 17 patients, using pocket debridement, iodine packing, and creation of a new pocket. Griffith et $\mathrm{al}^{12}$ described $74 \%$ success rate with pocket debridement, lead preservation, and creation of an ipsilateral, new subcutaneous pocket in patients with negative wound cultures. Kolker et $\mathrm{al}^{23}$ presented six patients treated with debridement, capsulectomy, pocket change to a fresh subcutaneous location, and local rhomboid skin flap closure, with five out of six (83\%) achieving long-term successful salvage. This technique carries the risk of additional donor site morbidity, since adjacent tissue must be harvested and rotated into the primary defect.

Many of these techniques need prolonged duration of the treatment using irrigation or dressings. Also, all these techniques entail usage of subcutaneous pocket plane for fresh implantation that continues to be prone to erosion, exposure, or infection.

Subpectoral positioning of CIED, aimed at providing more durable coverage against erosion and exposure in frail patients, was described in 1995 by Foster et al in six patients using a lateral approach. ${ }^{24}$ Soon after, in 1996, a comparison of primary placement of cardiac devices in the subpectoral space versus the traditional subcutaneous space was done that did not demonstrate significant differences in freedom from complications. ${ }^{25}$ Thus, worldwide practice is to use subcutaneous pocket to implant CIED, as procedural time is short and the procedure is technically less demanding. 
Subpectoral placement of CIED as a technique for salvage, and not primary placement, has been attempted by many investigators. Jenson ${ }^{26}$ described a case report of repositioning of a generator from an abdominal pocket to a subpectoral location, using an axillary tunnelling technique. Al-Bataineh et $\mathrm{al}^{27}$ described a lateral axillary approach to subpectoral plane in patients with ipsilateral prepectoral infection, with no recurrence of infection. There was one hematoma and one pneumothorax in the 16 patients treated. Lateral approach to subpectoral space requires greater dissection and is technically more demanding; it has not found widespread acceptance.

Knepp et $\mathrm{a}^{28}$ were the first to advocate anterior, muscle split approach to subpectoral space. Their technique, similar to ours, was used in seven patients with varied indications such as impending exposure, erosion, infection, hematoma at the time of initial placement, and cosmesis. Six patients (86\%) achieved long-term successful repositioning with no recurrent infection or exposure and good cosmetic results. The authors highlighted many advantages of the technique, including a clean plane, coverage with healthy vascularized muscle, and easy closure of the skin wound over the drains without need of complicated flaps. The authors preserved the leads, but exchanged the involved CIED with new generator device if not operating for cosmesis.

Jung et $\mathrm{al}^{29}$ described a series of 10 patients for salvage of the same exposed CIEDs by creating a new subcutaneous pocket 1 to $1.5 \mathrm{~cm}$ away from the involved area under local anesthesia and using closed suction drainage. However, none of their cases had overt signs of local sepsis. We believe that if the subcutaneous pocket failed at the initial instance, a new pocket in the same plane with exposed and infected CIED might not be successful again.

In our study, we used the subpectoral placement of the CIED for erosion, exposure, or infection in 12 patients, and none of them for cosmesis or hematoma. We were able to achieve successful long-term salvage in nine patients (75\%), using the same generator unit and the leads. Thus, in our experience, coverage by vascularized PM muscle is an effective technique in face of infected and exposed implantable device when a replacement with new generator unit might not be possible. Salvaging CIED has great implications for a low- and middle-income country like India, where a fresh expenditure to the tune of a few hundred thousand rupees might not be affordable. ${ }^{6}$

There are other potential advantages of salvaging CIED. Deep vein thrombosis (DVT) of upper limbs is a known complication of CIED, and changing the side puts both the upper limbs at risk of DVT. ${ }^{30}$ Awaiting a pacemaker device after explantation is also not entirely safe with high (36\%) rate of major adverse cardiac events reported while awaiting pacemaker implantation. ${ }^{31}$

\section{Limitation of the Present Study}

This is a retrospective observational descriptive study with inherent bias; also, the numbers are small.

\section{Strength of the Study}

A 30-month study is a reasonable time frame to follow-up for relapse of infection and to assess the durability against infection.

\section{Conclusion}

In carefully selected CIED infections, the local salvage methods can be safely attempted. Placement of the same device along with the lead systems in the subpectoral position via anterior muscle split approach is technically simple to perform, with favorable outcomes and low morbidity. We would recommend use of this approach as the first-line treatment if salvage is an option and contemplated.

\section{Funding}

None.

\section{Note}

The study was approved by Institutional Review Board (IRB) and Ethical Committee before commencement.

\section{Conflicts of Interest}

None declared.

\section{References}

1 Birnie D, Williams K, Guo A, et al. Reasons for escalating pacemaker implants. Am J Cardiol 2006;98(1):93-97

2 Goldberger Z, Lampert R. Implantable cardioverter-defibrillators: expanding indications and technologies. JAMA 2006;295(7):809-818

3 Zhan C, Baine WB, Sedrakyan A, Steiner C. Cardiac device implantation in the United States from 1997 through 2004: a population-based analysis. J Gen Intern Med 2008;23(Suppl 1):13-19

4 Baddour LM, Epstein AE, Erickson CC, et al. American Heart Association Rheumatic Fever, Endocarditis, and Kawasaki Disease Committee; Council on Cardiovascular Disease in Young; Council on Cardiovascular Surgery and Anesthesia; Council on Cardiovascular Nursing; Council on Clinical Cardiology; Interdisciplinary Council on Quality of Care; American Heart Association. Update on cardiovascular implantable electronic device infections and their management: a scientific statement from the American Heart Association. Circulation 2010;121(3):458-477

5 Sandoe JA, Barlow G, Chambers JB, et al. British Society for Antimicrobial ChemotherapyBritish Heart Rhythm SocietyBritish Cardiovascular SocietyBritish Heart Valve SocietyBritish Society for Echocardiography. Guidelines for the diagnosis, prevention and management of implantable cardiac electronic device infection. Report of a joint Working Party project on behalf of the British Society for Antimicrobial Chemotherapy (BSAC, host organization), British Heart Rhythm Society (BHRS), British Cardiovascular Society (BCS), British Heart Valve Society (BHVS) and British Society for Echocardiography (BSE. J Antimicrob Chemother 2015;70(2):325-359

6 Voigt A, Shalaby A, Saba S. Continued rise in rates of cardiovascular implantable electronic device infections in the United States: temporal trends and causative insights. Pacing Clin Electrophysiol 2010;33(4):414-419 
7 Kusumoto FM, Schoenfeld MH, Wilkoff BL, et al. 2017 HRS expert consensus statement on cardiovascular implantable electronic device lead management and extraction. Heart Rhythm 2017;14(12):e503-e551

8 Gutiérrez Carretero E, Arana Rueda E, Lomas Cabezas JM, et al. Infections in cardiac implantable electronic devices: diagnosis and management in a referral center. Rev Esp Cardiol (Engl Ed 2017;70(5):355-362

9 Yamada M, Takeuchi S, Shiojiri Y, et al. Surgical lead-preserving procedures for pacemaker pocket infection. Ann Thorac Surg 2002;74(5):1494-1499, discussion 1499

10 Hurst LN, Evans HB, Windle B, Klein GJ. The salvage of infected cardiac pacemaker pockets using a closed irrigation system. Pacing Clin Electrophysiol 1986;9(6):785-792

11 Lee JH, Geha AS, Rattehalli NM, et al. Salvage of infected ICDs: management without removal. Pacing Clin Electrophysiol 1996;19(4 Pt 1):437-442

12 Griffith MJ, Mounsey JP, Bexton RS, Holden MP. Mechanical, but not infective, pacemaker erosion may be successfully managed by re-implantation of pacemakers. Br Heart J 1994;71(2):202-205

13 Chang N, Mathes SJ. Comparison of the effect of bacterial inoculation in musculocutaneous and random-pattern flaps. Plast Reconstr Surg 1982;70(1):1-10

14 Durante-Mangoni E, Mattucci I, Agrusta F, Tripodi MF, Utili R. Current trends in the management of cardiac implantable electronic device (CIED) infections. Intern Emerg Med 2013;8(6):465-476

15 Sohail MR, Uslan DZ, Khan AH, et al. Management and outcome of permanent pacemaker and implantable cardioverter-defibrillator infections. J Am Coll Cardiol 2007;49(18):1851-1859

16 Rusanov A, Spotnitz HM. A 15-year experience with permanent pacemaker and defibrillator lead and patch extractions. Ann Thorac Surg 2010;89(1):44-50

17 Tarakji KG, Chan EJ, Cantillon DJ, et al. Cardiac implantable electronic device infections: presentation, management, and patient outcomes. Heart Rhythm 2010;7(8):1043-1047

18 Farooqi FM, Talsania S, Hamid S, Rinaldi CA. Extraction of cardiac rhythm devices: indications, techniques and outcomes for the removal of pacemaker and defibrillator leads. Int J Clin Pract 2010;64(8):1140-1147

19 Viola GM, Awan LL, Ostrosky-Zeichner L, Chan W, Darouiche RO. Infections of cardiac implantable electronic devices: a retrospective multicenter observational study. Medicine (Baltimore 2012;91(3):123-130
20 Taylor RL, Cohen DJ, Widman LE, Chilton RJ, O'Rourke RA. Infection of an implantable cardioverter defibrillator: management without removal of the device in selected cases. Pacing Clin Electrophysiol 1990;13(11 Pt 1) :1352-1355

21 Gupta S, Prevel CD, Shaheen K, et al. Wound complications and treatment of the infected implantable cardioverter defibrillator generator. J Card Surg 1993;8(6):671-677

22 Har-Shai Y, Amikam S, Ramon Y, Kahir G, Hirshowitz B. The management of exposed cardiac pacemaker pulse generator and electrode using restricted local surgical interventions; subcapsular relocation and vertical-to-horizontal bow transposition techniques. Br J Plast Surg 1990;43(3):307-311

23 Kolker AR, Redstone JS, Tutela JP. Salvage of exposed implantable cardiac electrical devices and lead systems with pocket change and local flap coverage. Ann Plast Surg 2007;59(1):26-29, discussion 30

24 Foster $\mathrm{AH}$. Technique for implantation of cardioverter defibrillators in the subpectoral position. Ann Thorac Surg 1995;59(3):764-767

25 Gold MR, Peters RW, Johnson JW, Shorofsky SR; Worldwide Jewel Investigators. Complications associated with pectoral cardioverter-defibrillator implantation: comparison of subcutaneous and submuscular approaches. J Am Coll Cardiol 1996;28(5):1278-1282

26 Jensen SM. Reposition of an implantable cardioverter defibrillator generator from an abdominal pocket to a subpectoral location using the existing electrode. Pacing Clin Electrophysiol 1998;21(3):627-628

27 Al-Bataineh M, Sajadi S, Fontaine JM, Kutalek S. Axillary subpectoral approach for pacemaker or defibrillator implantation in patients with ipsilateral prepectoral infection and limited venous access.J Interv Card Electrophysiol 2010;27(2):137-142

28 Knepp EK, Chopra K, Zahiri HR, Holton Iii LH, Singh DP. An effective technique for salvage of cardiac-related devices. Eplasty 2012;12:e8

29 Jung CY, Kim TG, Kim SE, Chung KJ, Lee JH, Kim YH. Safe and simplified salvage technique for exposed implantable cardiac electronic devices under local anesthesia. Arch Plast Surg 2017;44(1):42-47

30 van Rooden CJ, Molhoek SG, Rosendaal FR, Schalij MJ, Meinders AE, Huisman MV. Incidence and risk factors of early venous thrombosis associated with permanent pacemaker leads. J Cardiovasc Electrophysiol 2004;15(11):1258-1262

31 Risgaard B, Elming H, Jensen GV, Johansen JB, Toft JC. Waiting for a pacemaker: is it dangerous? Europace 2012;14(7):975-980 